\title{
Interdisciplinary science education and "origin of life": An exemplification with teaching aids
}

\author{
Toratane Munegumi \\ Department of Science Education, Naruto University of Education, Naruto, Tokushima 772-8502, Japan
}

Email address:

tmunegumi@naruto-u.ac.jp

\section{To cite this article:}

Toratane Munegumi.Interdisciplinary Science Education and "Origin of Life": An Exemplification with Teaching Aids.Science Journal of Education. Vol. 1, No. 2, 2013, pp. 20-27. doi: 10.11648/j.sjedu.20130102.11

\begin{abstract}
The new Japanese Government Curriculum Guidelines include new core ideas (energy, particle, life, and earth) for the curriculum in elementary and secondary science education. Although there is some integration of these core ideas when teaching different subjects, the learning items in different subjects (physics, chemistry, biology, and earth sciences) are separated strictly at the secondary school level. However, teaching the integrated items across some subjects is important for students to understand natural phenomena from various viewpoints. This article surveys the new Japanese Government Curriculum Guidelines, whose core idea includes a learning item "Origin of Life", and presents clear examples of segmentation of the core ideas. The directional properties of expansive learning can integrate into teaching based on the commonalities of core science ideas found in the curricula inthe USA, and Japan. This article also demonstrates an example of teaching aids for Origin of Life.
\end{abstract}

Keywords: Segmentation, Disciplinary Core Ideas, Origin of Life, Chirality, Origami Molecular Model

\section{Introduction}

The topic "Origin of Life" belongs to the multidisciplinary science field [1] comprising the overlap of chemistry, physics, biology, and earth science. A noted monograph, The Origin of Life on the Earth written by Miller and Orgel, showed that the topic Origin of Life exists in the multidisciplinary field [1]. Origin of Life is the science [2] of the relationship between environment, matter, and organisms.Many researchers in the interdisciplinary fields related to Origin of Life work within different fields, and they investigate Origin of Life from widely different viewpoints. Such diversity of investigation requires integration and innovation to answer definitively questions about the Origin of Life. At present, the integration of research into a coherent model of the Origin of Life provides important tools and viewpoints to help ensure the survival of humans and the sustainability of earth materials. Even though researchers in this field come from and represent different viewpoints - chemistry [3], biology [4], physics [5], and earth sciences [6, 7]-they usually understand what their colleagues are thinking. However, it is difficult for the average citizen to understand the relationships between the Origin of Life and everyday issues such as sustainability and the environment.
Elementary and secondary schools, and higher education, are important in the education of citizens. This study surveys the Japanese Government Curriculum Guidelines [8] and $\mathrm{K}-12$ framework of science education in the USA [9] and provides an example of a teaching aid at the high school level to demonstrate the importance of the topic Origin of Life in science education.

\section{Description of Origin of Life in the Japanese Government Curriculum Guidelines}

The Japanese Ministry of Education produced the new Government Curriculum Guidelines in 2008 and 2009 [8]. The Guidelines include Origin of Life as a new educational item in the study of Biology in high school. Although Origin of Life has been included in high school textbooks for Biology, this was the first time for inclusion of Origin of Life in the Government Curriculum Guidelines (Table 1) The Guidelines also include the new framework comprising the four core ideas: energy, particle, life, and earth (Table 2).

Table 1 shows the contents of the new Biology subjects: Basic Biology and Advanced Biology. Basic Biology 
explains that understanding Origin of Life of modern organisms is essential for understanding commonality and diversity. The content, range and level of Advanced Biology describe understanding Origin of Life, transition of life, and system of evolution as goals.

Table 1. Description of the Origin of Life in the Japanese Government Curriculum Guidelines

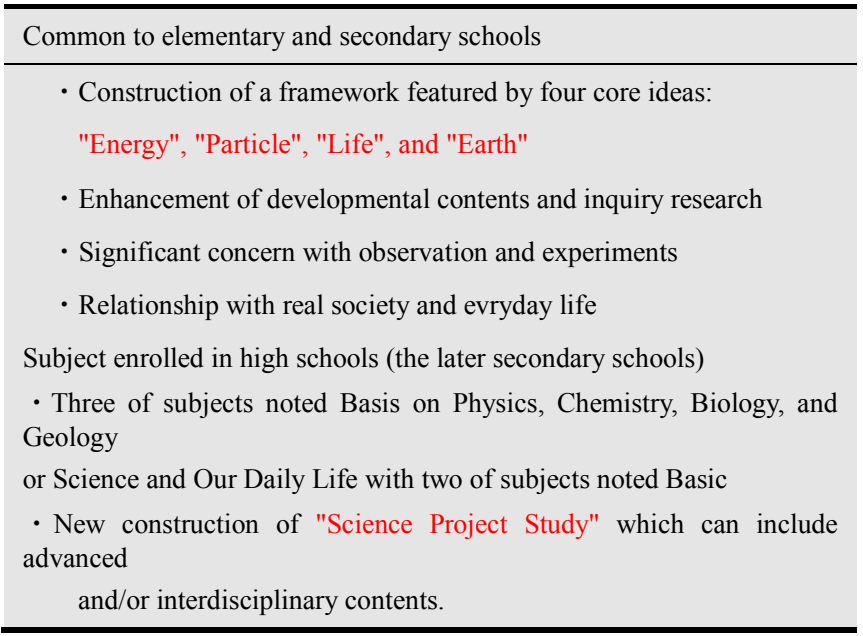

*The contents of the table were translated from the Japanese original Guidelines by the author.

Table 2 shows the framework based on the four core ideas through elementary school and high school, developmental and inquiry content, observation and experimental content, and relationship with real life. The minimum number of required subjects in high school is also shown.

Table 2. New revision of Science in the Japanese Government Curriculum Guideline

\begin{tabular}{l} 
Goal of "Basic Biology" \\
\hline To understand the two viewpoints, commonality and diversity, \\
it is important for students to understand that the present \\
lives have their origin as basis of commonality and diversity. \\
Content, range, and level of"Advanced Biology" \\
(5) Evolution and phylesis of life \\
A. Evolution and system of life \\
(a) Origin of life and transition of life \\
Understanding origin of life and line of biological evolution \\
(b) System of evolution \\
Understanding how biological evolution occurs
\end{tabular}

*The contents of the table were translated from the Japanese original Guidelines by the author.

The previous Government Curriculum Guidelines did not include the core ideas, but instead included four disciplinary subjects: physics, chemistry, biology, and earth science. The disciplinary subjects were sectioned strictly without any overlap in their educational content, although integration of some science subjects was included. However, the appearance of the core ideas suggests that the boundaries between the conventional subjects: physics, chemistry, biology, and earth science have become more flexible.

Figure 1 shows the boundaries between conventional science subjects, and Figure 2 shows the boundaries between the core ideas. The boundaries between the conventional subjects are very clear and do not include any overlap. The Government Curriculum Guidelines [8] strongly regulate the subject matter of textbooks, and there is little overlap of topics and educational items in the textbooks of different subjects. However, there is some freedom of interpretation by publishers, who may display some bias in the terms of the level and topics included in a textbook on a particular subject. The educational item Origin of Life was included in several textbooks before the new Guidelines. For example, figures of the Miller experiment and other descriptions relating to Origin of Life can be found in both the old and new high school textbooks for Advanced Biology.

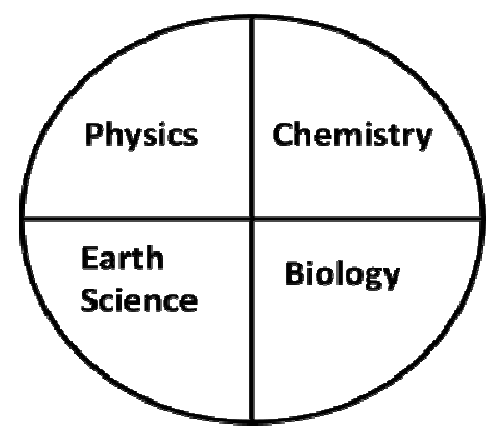

Figure 1. Boundaries between conventional science subjects.

Figure 2 shows the indistinct and overlapping boundaries between the four core ideas, although energy, particle, life, and earth indicate physics, chemistry, biology, and earth science, respectively. Originally, each core idea has some ambiguity and its meaning may be expanded to produce flexible boundaries and overlap of some topics. However, introduction of these core ideas allows the teachers and publishers to integrate Origin of Life into science education because it lies within the intersection between the four core ideas.

The four interdisciplinary [10] areas can be grouped into fields of two overlapping disciplines: (1) physics and chemistry; (2) chemistry and biology; (3) biology and earth science; and (4) earth science and physics. Two other theoretical overlapping areas are (5) chemistry and earth science, and (6) physics and biology, which are included in areas (1) to (4) described above. Origin of Life has been investigated from the viewpoints of physics, chemistry, biology, and earth science. For example, the thermal properties of organisms and their evolutionary changes have been investigated within physics, chemistry, and biology. The environment in which the first organism was 
born has been investigated in physics, chemistry, biology, and earth science. The chirality of compounds used in the construction of organisms has been investigated in chemistry, biology, and physics. As shown in these examples, the topic Origin of Life lies within the multidisciplinary area of all the disciplinary areas: physics, chemistry, biology, and earth science. Therefore, each science subject can examine the topic from its particular viewpoint.

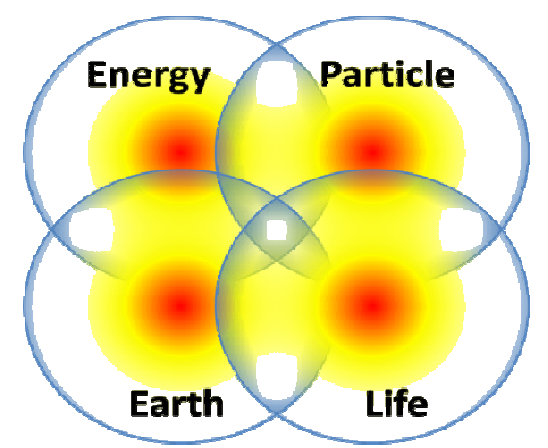

Figure 2.The four core ideas and their boundaries.

However, clear lines are drawn in the boundaries between all science subjects in Japan. The topic Origin of Life is included in biology but not in physics, chemistry, or earth science. The textbooks used in high school are also strictly segmented as required by the Government Curriculum Guidelines. Strict segmentation between science subjects conflicts with the more flexible image of the four core ideas. Some directions can be taken to ensure that Origin of Life is included in the developmental content of textbooks or class room teaching and in the new subject Science Project Study in the Government Curriculum Guidelines. There is some freedom in the developmental content, expansive learning, and Science Project Study. Teachers may select topics that overlap the interdisciplinary areas of science. The Japanese approach to interdisciplinary science areas such as Origin of Life is narrow and sectarian in subjects; by contrast, the approach in the USA is wider and more flexible than that in the Government Curriculum Guidelines in Japan.

\section{Comparison with Framework for K-12 Science Education}

Figure 3 shows a three-dimensional framework proposed by the US National Research Council. The Framework [9] comprises three dimensions: Dimension 1, Scientific and Engineering Practices; Dimension 2, Crosscutting Concepts; and Dimension 3, Disciplinary Core Ideas.

Dimension 1 (Scientific and Engineering Practices) includes eight practices: (1) Asking questions (for science) and defining problems (for engineering); (2) Developing and using models; (3) Planning and carrying out investigations; (4) Analyzing and interpreting data; (5) Using mathematics and computational thinking; (6)
Constructing explanations (for science) and designing solutions (for engineering); (7) Engaging in argument from evidence; and(8) Obtaining, evaluating, and communicating information.

Dimension 2 (Crosscutting Concepts) includes seven practices: (1) Patterns; (2) Cause and effect: mechanism and prediction; (3) Scale, proportion, and quantity; (4) Systems and system models; (5) Energy and matter: flows, cycles, and conservation; (6) Structure and function; and (7) Stability and change.

Dimension 3 (Disciplinary Core Ideas) includes four practices: (1) Physical Sciences; (2) Life Sciences; (3) Earth and Space Sciences; and (4) Engineering, Technology, and Applications of Sciences.

This article focuses on Dimensions 2 and 3 in detail, and less on Dimension 1, which relates more to engineering and technology.

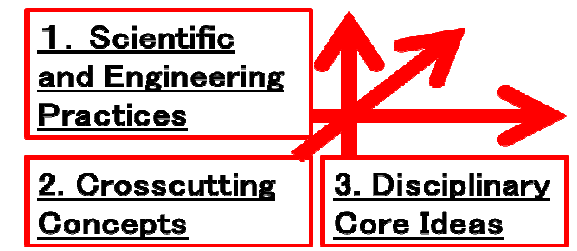

Figure 3. 3D Framework for K-12 science education [9]. The squares and arrows were added and arranged by the author

A typical feature of Dimension 2 is that it proposes interdisciplinary or multidisciplinary viewpoints to understand natural phenomena. Therefore, it provides crosscutting methods to examine different phenomena. For example, within (1) Patterns, Chapter 4 of "A Framework for K-12 Science Education" explains that "patterns are discernible in the symmetry of flowers and snowflakes, the cycling of the seasons, and the repeated base pairs of DNA." Chapter 4 also says "In this chapter, we describe concepts that bridge disciplinary boundaries, having explanatory value throughout much science and engineering." The phrase "bridge disciplinary boundaries" is the most important purpose of Dimension 2.

Dimension 3 (Disciplinary Core Ideas) characterizes four disciplinary fields, each of which is constructed from several core ideas, as shown in Table 3 . These core ideas are more detailed and clearer than are the Japanese core ideas. For example, physical sciences (PS) has four core ideas: PS1, Matter and its Interaction; PS2, Motion and Stability: Force and Interactions; PS3, Energy; and PS4, Waves and their Applications in Technology for Information Transfer. Further, each core idea is characterized by three or four component ideas. For example, PS1 (Matter and Its Interaction) has three component ideas: PS1.A, Structure and Properties of Matter; PS1.B, Chemical Reactions; and PS1.C, Nuclear Processes. These core ideas and component ideas provide a more detailed and finer explanation of Energy and Particle than do the Japanese core ideas. It is very difficult to represent the contents of physics using only one core idea such as Energy or chemistry using only one core idea such 
as Particle. The system of Japanese core ideas of science education is less detailed and therefore ambiguous. It is impossible to represent one disciplinary by one core idea.

The core ideas of the US K-12 Science Education are superior to those of Japanese. The core ideas and component ideas of $\mathrm{K}-12$ Science Education represent the overlap between disciplinary fields using the same keywords. For example, a keyword "Matter" can be seen in PS1, PS1.A, LS1.C, and LS2.B, showing that this term is a common keyword for both Physical Sciences and Life Sciences. The keyword "Interaction" can be seen in PS1, PS2, LS2, and LS2.D. "Energy" can be seen in PS3, PS3.A, PS3.B, PS3.C, PS3, PS3.D, LS1.C, LS2, and LS2.B. The prefix "Bio-" can be seen in LS4, LS4.D, and ESS2.E. The keyword "Human" can be seen in LS4.D, ESS3, and ESS3.C. The phrase "Everyday Life", which has a similar meaning to "Human Activity" is included in both ESS3 and PS3.D. These represent extensive overlapping between Physical Sciences, Life Sciences, and Earth and Space Sciences.

Several core ideas and core components related to Origin of Life can be extracted as follows: Chemical Reactions (PS1.B); From Molecules to Organisms: Structure and Processes (LS1); Biological Evolution: Unity and Diversity (LS4); and Biogeology (ESS2.E). These are typical keywords but not all those included in the names of core ideas and core components, although other core ideas and components related to Origin of Life may be found. The extraction and classification described above strongly demonstrate that a topic such as Origin of Life can be included within the multidisciplinary area between conventional subjects.

The Framework for $\mathrm{K}-12$ Science Education proposed by the US National Research Council influences science education in the USA and forms the basis of the program Science Education for the Next Generation. The framework is based on a proposal Next Generation Science Standards, through which many states create the standards for their own science education.

Table 3.Core Ideas of $K-12$ Science Education.

\begin{tabular}{lll}
\hline Segment & Core and Component Ideas & $\begin{array}{l}\text { Overlapping } \\
\text { keywords }\end{array}$ \\
\hline PS1: & Matter and Its Interaction & $\begin{array}{l}\text { Matter, Interaction } \\
\text { Matter }\end{array}$ \\
PS1.A: & Structure and Properties of Matter & \\
PS1.B: & Chemical Reactions & \\
PS1.C: & Nuclear Processes & Interaction \\
PS2: & Motion and Stability: Forces and & \\
PS2.A: & Interactions & \\
PS2.B: & Forces and Motion & \\
PS2.C: & Stability and Instability in Physical & \\
PS3: & Systems & Energy \\
PS3.A: & Definitions of Energy & Energy \\
PS3.B: & Conservation of Energy and Energy & Energy \\
PS3.C: & Transfer & Relationship Between Energy and \\
\hline
\end{tabular}

\begin{tabular}{|c|c|c|}
\hline Segment & Core and Component Ideas & $\begin{array}{l}\text { Overlapping } \\
\text { keywords }\end{array}$ \\
\hline PS3.D: & $\begin{array}{l}\text { Energy in Chemical Processes and } \\
\text { Everyday Life }\end{array}$ & Energy, Life \\
\hline PS4: & $\begin{array}{l}\text { Waves and Their Applications in } \\
\text { Technologies for Information Transfer }\end{array}$ & \\
\hline PS4.A: & Wave Properties & \\
\hline PS4.B: & Electromagnetic Radiation & \\
\hline PS4.C: & $\begin{array}{l}\text { Information Technologies and } \\
\text { Instrumentation }\end{array}$ & \\
\hline LS1: & $\begin{array}{l}\text { From Molecules to Organisms: } \\
\text { Structure and Processes }\end{array}$ & \\
\hline LS1.A: & Structure and Function & \\
\hline LS1.B: & $\begin{array}{l}\text { Growth and Development of } \\
\text { Organisms }\end{array}$ & \\
\hline LS1.C: & $\begin{array}{l}\text { Organization for Matter and Energy } \\
\text { Flow in Organisms }\end{array}$ & Matter, Energy \\
\hline LS1.D: & Information Processing & \\
\hline LS2: & $\begin{array}{l}\text { Ecosystems: Interactions, Energy, and } \\
\text { Dynamics }\end{array}$ & $\begin{array}{l}\text { Interaction, } \\
\text { Energy }\end{array}$ \\
\hline LS2.A: & $\begin{array}{l}\text { Interdependent Relationships in } \\
\text { Ecosystems }\end{array}$ & \\
\hline LS2.B: & $\begin{array}{l}\text { Cycles of Matter and Energy Transfer } \\
\text { in Ecosystems }\end{array}$ & Matter, Energy \\
\hline LS2.C: & $\begin{array}{l}\text { Ecosystem Dynamics, Functioning, } \\
\text { and Resilience }\end{array}$ & \\
\hline LS2.D: & $\begin{array}{l}\text { Social Interactions and Group } \\
\text { Behavior }\end{array}$ & Interaction \\
\hline LS3: & $\begin{array}{l}\text { Heredity: Inheritance and Variation of } \\
\text { Traits }\end{array}$ & \\
\hline LS3.A: & Inheritance of Traits & \\
\hline LS3.B: & Variation of Traits & \\
\hline LS4: & $\begin{array}{l}\text { Biological Evolution: Unity and } \\
\text { Diversity }\end{array}$ & Bio- \\
\hline LS4.A: & $\begin{array}{l}\text { Evidence of Common Ancestry and } \\
\text { Diversity }\end{array}$ & \\
\hline $\begin{array}{l}\text { LS4.B: } \\
\text { LS4 C. }\end{array}$ & Natural Selection & \\
\hline LS4.D: & Biodiversity and Humans & Human, Bio- \\
\hline ESS1: & Earth's Place in the Universe & \\
\hline ESS1.A: & The Universe and Its Stars & \\
\hline ESS1.B: & Earth and the Solar System & \\
\hline ESS1.C: & The History of Planet Earth & \\
\hline ESS2: & Earth's Systems & \\
\hline ESS2.A: & Earth Materials and Systems & \\
\hline ESS2.B: & $\begin{array}{l}\text { Plate Tectonics and Large-Scale } \\
\text { System Interactions }\end{array}$ & Interaction \\
\hline ESS2.C: & $\begin{array}{l}\text { The Roles of Water in Earth's Surface } \\
\text { Processes }\end{array}$ & \\
\hline ESS2.D: & Weather and Climate & \\
\hline ESS2.E: & Biogeology & Bio- \\
\hline ESS3: & Earth and Human Activity & Human \\
\hline ESS3.A: & Natural Resources & \\
\hline ESS3.B: & Natural Hazards & \\
\hline ESS3.C: & Human Impacts on Earth Systems & Human \\
\hline ESS3.D: & Global Climate Change & \\
\hline ETS1: & Engineering Design & \\
\hline ETS1.A: & $\begin{array}{l}\text { Defining and Delimiting an } \\
\text { Engineering Problem }\end{array}$ & \\
\hline ETS1.B: & Developing Possible Solutions & \\
\hline ETS1.C: & Optimizing the Design Solution & \\
\hline ETS2: & $\begin{array}{l}\text { Links among Engineering, Technology, } \\
\text { Science, and Society }\end{array}$ & \\
\hline ETS2.A: & $\begin{array}{l}\text { Interdependence of Science, } \\
\text { Engineering, and Technology }\end{array}$ & \\
\hline ETS2.B: & $\begin{array}{l}\text { Interdependence of Engineering, } \\
\text { Technology, and Science on Society } \\
\text { and the Natural World }\end{array}$ & \\
\hline
\end{tabular}


A comparison of science education as depicted in the Government Curriculum Guidelines in Japan with the Framework for K-12 Science Education in the USA shows that the Japanese approach involves clear segmentation between subjects but that the US approach involves bridging between multidisciplinary teaching items.

\section{An Example of Teaching Aids for Origin of Life}

\subsection{Teaching Aids for Origin of Life in Biology Textbooks in Japan}

As described above, the topic Origin of Life appears in only Basic Biology and Advanced Biology for high school in the Government Curriculum Guidelines of Japan. However, it is possible to include this topic within interdisciplinary fields in developmental contents, expansive learning, or Science Project Study. Some high school Advanced Biology textbooks include an experimental description of Coacervate as a teaching aid for the study of the Origin of Life. Everybody knows the experiment-Coacervation as a model of primitive cell formation. The Coacervation experiment uses common modern natural organic materials such as gelatin and gum Arabic_-protein and polysaccharide, respectively. However, these compounds could not have formed in the primitive Earth before the first organisms appeared. The Coacervation experiment does not represent actual primitive cell formation, but a kind of particle formation from current organic materials described by Alexander Oparin in his notebook, The Origin of Life [11].This experiment has some value as a teaching aid, although the teachers should explain that the experiment is not actual primitive cell formation but just a model of how primitive cells formed and that the purpose of the experiment is to understand the history of the research on Origin of Life.

\subsection{A Direction for Teaching Aids of Origin of Life}

As discussed above, the teaching aids of Origin of Life are acceptable in science education with the proper explanation, even if the teaching aids might not represent the actual process of Origin of Life. There can be many approaches from the conventional disciplinary subjects (physics, chemistry, biology, and earth sciences) to Origin of Life, since the teaching item, Origin of Life exists in the multidisciplinary field.Coacervate may be characterized as a teaching aid from biology. However, there are no teaching aids from other disciplinary fields in Japanese science textbooks, although teachers may explain the Origin of Life from the perspective of other fields.

I present an example of an interdisciplinary teaching aid for Origin of Life from chemistry to change the restrictions imposed by the segmented disciplinary subjects. I hope that this example will lead to the integration of science education about global and universal issues in Japan, and will provide some understanding of Origin of Life. My approach starts with a chemical discussion and focuses on chirality and organisms.

The process of Origin of Life involves mainly the chemical evolution, as proposed by Alexander Oparin. Many scientists believe in chemical evolution in the universe and in biological evolution on the Earth. Origin of Life is the result of chemical evolution, and biological evolution is a result of Origin of Life. Living forms comprise cells constructed with proteins, polysaccharides, polynucleotides, lipids, other organic compounds, and inorganic compounds. There are many approaches to illustrate the formation process for each compound in abiotic conditions and the interaction between these compounds before cells appeared in evolution. The teaching aids for Origin of Life need visual clarity, proper impact, a story, and a good explanation, in addition to the teaching aids needed for other educational items.

\subsection{Origami Molecular Models of Amino Acids}

Although many kinds of compounds and systems may provide useful models [12], I focus on molecular models of amino acids using paper craft (origami [13, 14]), which can provide a clear method to visualize and recognize differences in shape and are easy to make. To do so, I start by explaining the structural relationships between origami amino acids, real amino acids and the chirality of amino acids in the context of Origin of Life. The story of chirality and Origin of Life, the relationship between origami and amino acids, and origami molecular models of amino acids are shown in ways that can be applied in the classroom (Figure 4).

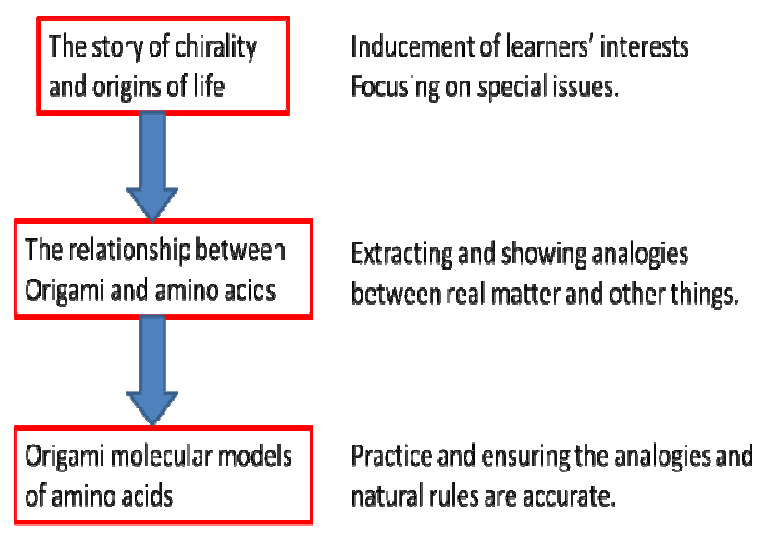

Figure 4.A flow chart of teaching Origin of Life in the classroom

\subsubsection{The Story of Chirality and Origin of Life}

The human body has a right hand and a left hand. These hands are very similar but different: both hands have five fingers, and if one looks at the right hand in the mirror, it is almost the same as the left hand. We can call this relationship a mirror image. We can also see the same relationship in molecules. There are right-handed molecules and left-handed molecules in nature. Amino acids are typical examples (Figure 5). 


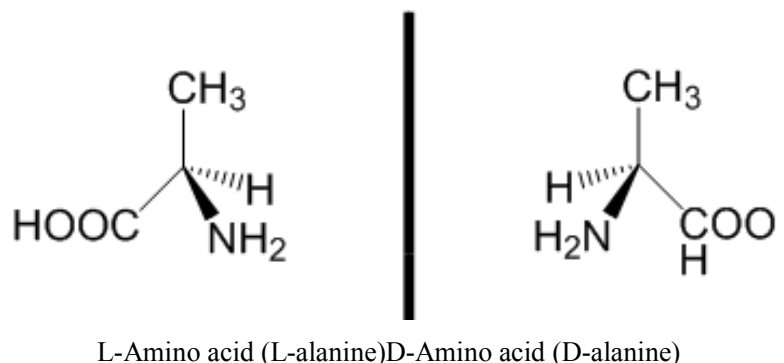

Figure 5. Mirror image structures of an amino acid (alanine).

However, only one-hand-structured (so-called homochiral) amino acids, which are called L-amino acids, make proteins. The mirror image structures to L-amino acids are called D-amino acids. Proteins are constructed by linking more than 50 amino acids, and proteins have a kind of homochirality to form chemically functional three-dimensional structures with biological functions. If proteins have evolved comprising a mixture of L- and D-amino acids, proteins would not show as much variety of biological functions as seen in present day organisms. Therefore, the homochirality of amino acids is closely related to biological function. There are two directions of thinking about the relationship between homochirality of proteins and Origin of Life. One is based on the hypothesis that organisms acquired homochirality in their proteins before the Origin of Life. The other is based on the hypothesis that organisms acquired homochirality after the Origin of Life. However, the time when organisms acquired homochirality is not clear.

\subsubsection{The Relationship between Origami and Amino Acid}

We can make mirror image-structured materials such as amino acids using various materials (Figure 6). A pair of shoes provides a good example of a mirror image-structured material used in our everyday life. However, deforming the structure of shoes to a simpler style will make it difficult for learners to recognize the mirror image relationship. Origami, which is a Japanese paper craft, is an interesting material to show the deformation of structure of many kinds of matter because origami is soft, flexible, and easy to bend, but creates a strong structure.

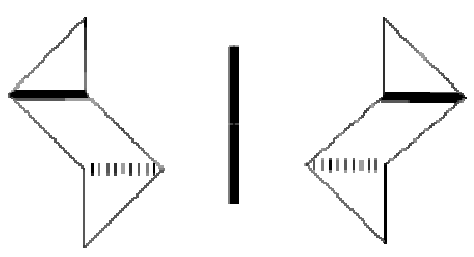

Figure 6. Examples of mirror image structures: a pair of origami paper craft showing mirror image structures of each other.

\subsubsection{Origami Molecular Models of Amino Acids}

Origami molecular models to show the mirror image of amino acids can be made from many shapes of origami paper (Figure 7). This article uses examples published in a Japanese paper [12]. The origami molecular models have been reported as an example of a mirror image structure [12] but have not been shown as special models of amino acids. However, the models can be applied to peptides because of their structure involving an adaptor and acceptor.

One right-handed structure (8b) adopts the spiny triangle moiety of the other right-handed structure (7b) to form a dimer of a right-handed structure (Figure 8). This is an analogous structure of a dipeptide of an L-amino acid. We can repeat the same procedure to make an analogous structure of an L-polypeptide (9b). We can also make a left-handed polypeptide from the antipode of the right-handed structure. Interestingly, the analogous structures $(7 \mathrm{a}, 8 \mathrm{a})$ of the left-handed polypeptide form a left-handed helix (10a), and the analogous structure of the right-handed polypeptide forms a right-handed helix (10b).

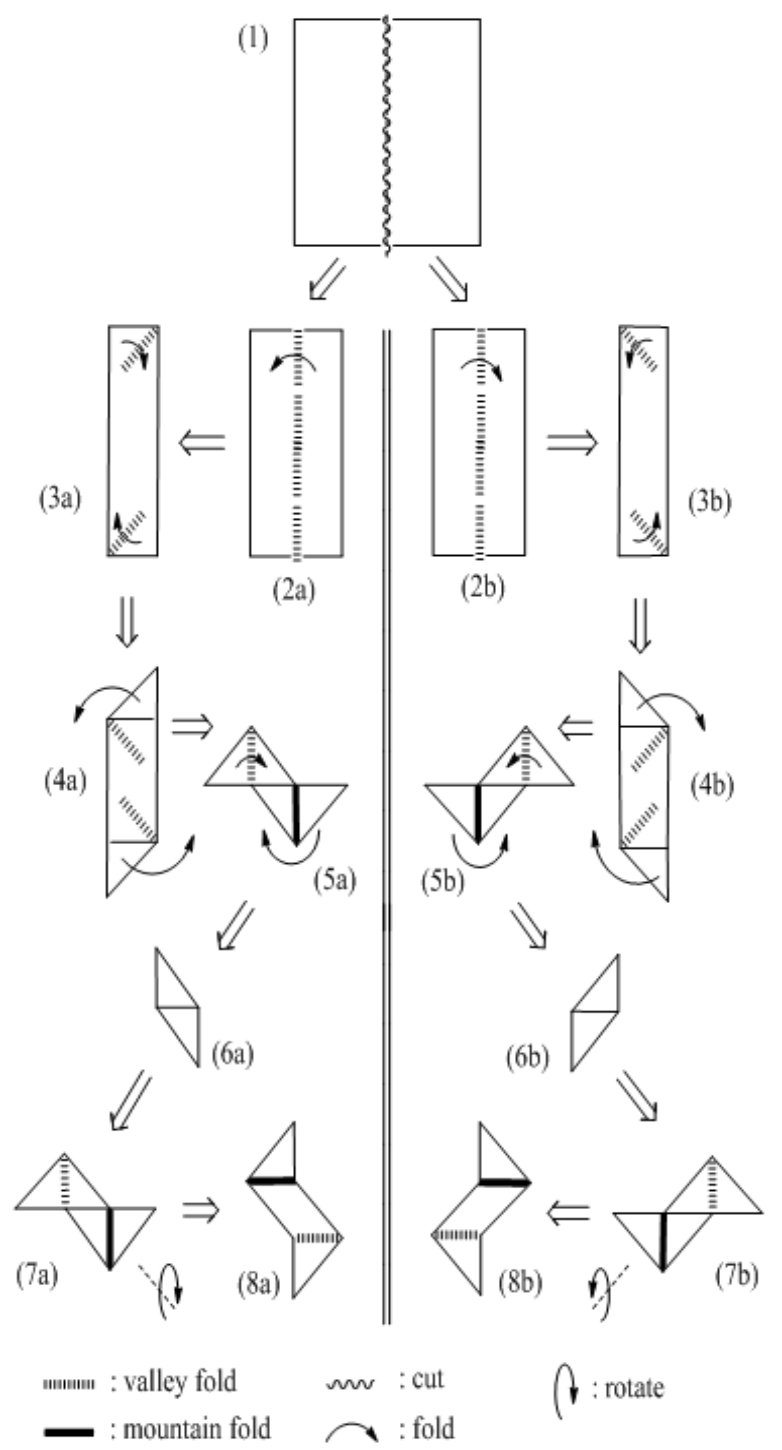

Figure 7. Procedure formaking origami modelsof amino acids.

Therefore, these origami molecular models can show the steric relationship between right- and left-handed polypeptides as well as the steric relationship between rightand left-handed amino acids. The origami molecular models 
can also demonstrate the significance of homochirality of amino acids in the chemical evolutionary process by building up the homochiral polypeptide models from a chiral amino acid model.

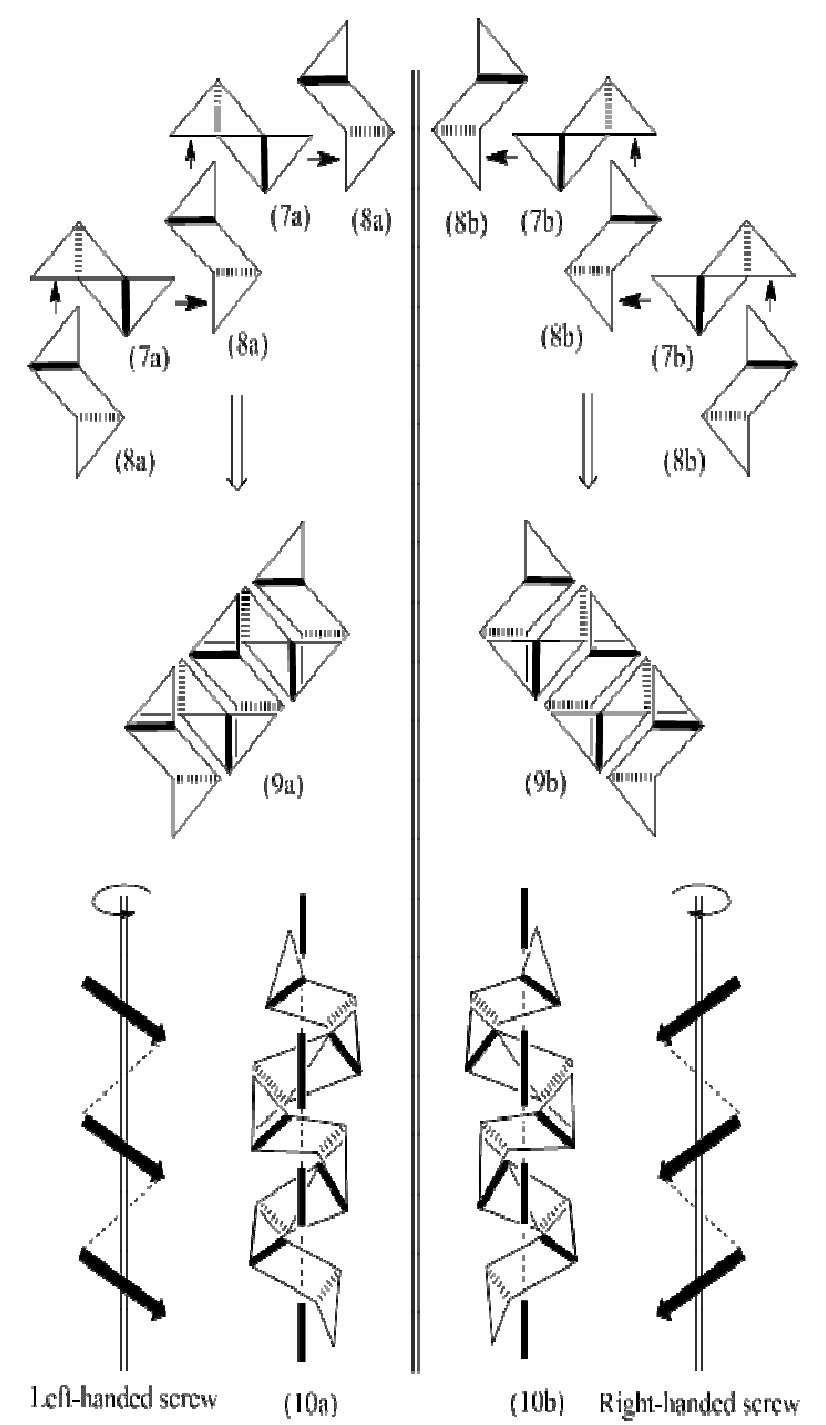

Figure 8.Peptide models constructed from origami amino acid models.

\subsubsection{The Relationship between Origami Molecular Model of Amino Acid and the Evolution of Homochirality to Origin of Life}

Left-handed Origami molecular models of amino acids may link each other to construct a left-handed helix structure as shown in Figure 8. Right-handed Origami molecular models construct a right-handed helix structure. The relationship is very similar to the relationship between L-amino acids and right-handed helix. It is very difficult to recognize the relationship using standard commercial molecular models because their original structure is not simple. However, the Origami molecular models can link each other to become the one-handed structure depending on the chiral monomer structure. We can see it a self-construction process of chiral amino acids to a homochiral structure. This is one of the processes of the evolution of homochirality to lead Origin of Life.The Origami molecular models demonstrate the similarity inthe self-construction of Origami molecular models to that of chiral amino acids.

\section{Direction of Science Education Related to Origin of Life}

As described above, Origin of Life is a multidisciplinary field between physics, chemistry, biology, and earth science. Although many areas represent in such multidisciplinary fields, study of the Origin of Life is essential when thinking about the survival of humans on Earth. Origin of Life can be studied at the intersection of organisms and the environment surrounding the organisms. Many issues concentrate in the area of Origin of Life and raise the following questions. What are the specific conditions under which organisms can be born and mature? What energy is essential for organisms? What chemicals are essential for organisms? What body structure is essential for organisms? What geological environment is essential for living? These issues are related to the area of Origin of Life. To understand the Origin of Life and how humans will survive, we need knowledge and patterns of thinking from the different fields of physics, chemistry, biology, and earth sciences. Discussing Origin of Life requires and leads to multidisciplinary and integrated scientific thinking.

\section{Conclusions}

(1) The core ideas of science education proposed by the Government Curriculum Guidelines in Japan include indistinct boundaries between conventional science subjects. Despite such changes in the perceptions of the boundaries between science subjects, these subjects are separated strictly in both conventional textbooks and in science subjects.

(2) Origin of Life appeared first in the new Government Curriculum Guidelines in Japan. Despite the multidisciplinary basis of Origin of Life, the issue is taught only in Basic Biology and Advanced Biology in high school.

(3) A comparison of science education proposed by the Government Curriculum Guidelines in Japan with the Framework for K-12 Science Education in the USA shows that the latter is more suitable for multidisciplinary thinking because it includes many overlapping core ideas and crosscutting concepts.

(4) The only way to deal with the multidisciplinary field Origin of Life is to teach students in expansive learning and in a new science subject Science Project Study in Japan.

(5) Origami molecular models are an example of a teaching aid for Origin of Life. In the classroom, the teacher could show how the origami molecular models of chiral amino acids comprise homochiral helix structures and could help the students understand the connections from amino 
acid homochirality to polypeptide homochirality, and further to the functionality of organisms constructed by homochiral polypeptides. Creating and using teaching aids from diverse fields will help students think about Origin of Life from multiple points of view.

\section{References}

[1] S. L., Miller,and L. E.Orgel. The Origins of Life on the Earth, Prentice-Hall, Inc., New Jersey, 1974.

[2] C. Zimmer. On the Origin of Life on Earth, Science, 323, 198-199, 2009.

[3] P. Herdewijn and M. V. Kisakurek Eds. Origin of Life Chemical Approach, Wiley-VCH, Zurich, 2008.

[4] S. W. Fox. The Emergence of Life Darwin Evolution from the Inside, Basic Books Inc., New York, 1988.

[5] M. Akaboshi, N. Fujii, and R. Navarro-Gonzalez Eds.The Role of Radiation in the Origin and Evolution of Life, Kyoto University Press, Kyoto, 2000.

[6] S. Nakashima, S. Maruyama, A. Brack, and B. F. Windley Eds.Geochemistry and the Origin of Life, University Academy Press, Inc., Tokyo, 2001.

[7] P. J. Thomas, R. D. Hicks, C. F. Chyba, and C. P. McKay Eds.Comets and the Origin and Evolution of Life, Springer,
Berlin Heidelberg, 2006

[8] Ministry of Education, Culture, Sports, Science and Technology:Government Curriculum Guidelines, 2008, 2009; http://www.mext.go.jp/a_menu/shotou/new-cs/youryou/inde x.htm.(access date: July 3 th,2013).

[9] National Research Council of the National Academies. Framework for k-12 Science Education,2012; http://www.nap.edu/openbook.php?record id=13165; http://www.nextgenscience.org/.

[10] C. M. Czerniak, Interdisciplinary science teaching, pp.538-559. In Handbook of research on science education, Eds. S. K. Abell and N. G. Lederman, Routledge Taylor \& Francis Group, New York, 2007.

[11] A. I. Oparin, The Origin of Life, English Translation Edition by S. Morgulis, Macmillan Company, New York, 1938.

[12] O. De Jong, K. S. Taber, teaching and learning the many faces of chemistry, pp.631-652. In Handbook of research on science education, Eds. S. K. Abell and N. G. Lederman, Routledge Taylor \& Francis Group, New York, 2007.

[13] T. Munegumi: Teaching device for stereochemical grasp of asymmetric organic molecules (2), Kosen Kyoiku, No. 18, pp. 17-21(1995).

[14] J. Garcia, R. Esparza, and R. Perez, Origami construction of $3 \mathrm{D}$ models for fullerenes, carbon nanotubes and associated structures, Chem. Educator, 14, 1-4 (2009). 